\title{
Evaluation of Ventilation System Efficiency with Reference to Ceiling Height in Warm-Humid Climate of Pakistan
}

\author{
Sadia Farooq ${ }^{1}$, Faiza Zubair², Mohammad Arif Kamal ${ }^{3, *}$ \\ ${ }^{1}$ Department of Science, University of Home Economics, Pakistan \\ ${ }^{2}$ Department of Family and Consumer Sciences, University of Home Economics, Pakistan \\ ${ }^{3}$ Architecture Section, Aligarh Muslim University, India
}

Received July 25, 2020; Revised August 31, 2020; Accepted September 29, 2020

\begin{abstract}
Cite This Paper in the following Citation Styles
(a): [1] Sadia Farooq, Faiza Zubair, Mohammad Arif Kamal, "Evaluation of Ventilation System Efficiency with Reference to the Ceiling Height in Warm-Humid Climate of Pakistan," Civil Engineering and Architecture, Vol. 8, No. 5, pp. 824 - 831, 2020. DOI: 10.13189/cea.2020.080509.
\end{abstract}

(b): Sadia Farooq, Faiza Zubair, Mohammad Arif Kamal (2020). Evaluation of Ventilation System Efficiency with Reference to the Ceiling Height in Warm-Humid Climate of Pakistan. Civil Engineering and Architecture, 8(5), 824 - 831. DOI: 10.13189/cea.2020.080509.

Copyright $\odot 2020$ by authors, all rights reserved. Authors agree that this article remains permanently open access under the terms of the Creative Commons Attribution License 4.0 International License

\begin{abstract}
This research is about the effectiveness of ventilation systems for human thermal comfort concerning the height of the ceilings which contribute to green building structures, especially for residential areas. One of the greatest challenges in architecture is the cost of mechanical ventilation and the need for energy demand for cooling in hot and humid climates. The study is based on quantitative data of the selected houses, keeping constant the areas, location, elevation features, plant placement, and open spaces. Temperature records for 20 days of 10 low ceiling houses $(\mathrm{LCH})$ and 10 high ceiling houses $(\mathrm{HCH})$ with ventilators, 200 observations each, are compared using independent sample t-test. The mean temperature is $15.31^{\circ} \mathrm{C}$ in $\mathrm{LCH}$ and $13.88^{\circ} \mathrm{C}$ in $\mathrm{HCH}$, with the difference of $1.43^{\circ} \mathrm{C}$ so the alternative hypothesis that there is a significant difference between the average temperature of $\mathrm{LCH}$ and $\mathrm{HCH}$ with ventilators, is accepted. The other benefits of ventilation cannot be ignored which we get in the high ceiling houses. This would also help to reduce moisture, smoke, odor, heat, dust, and bacteria.
\end{abstract}

Keywords Ventilation System, Ceiling Heights, Warm-Humid Climate, Pakistan

\section{Introduction}

The Globalization has a drawback to increase the energy demand with an impact on the environment such as pollution, ozone depletion, temperature increases, and above its scarcity of resources [1]. In the past few decades, houses are constructed with a low ceiling height which does not contribute much to the exchange of air from inside and outside. With all other professional challenges, architecture has to face to develop a living space with thermal comfort and to lessen the mechanical ventilation to control heat [2]. About 40\% of the global energy consumption is spent in the built environment [3]. There has been a lot of reliance on energy-consuming technology in cooling and ventilation system to achieve thermal comfort in buildings [4]. The spaces must be constructed to provide comfort to the users [5]. The inside space works on the phenomena of convection when air moves upward when it gets hot and cool air travels down [6] so in the hot humid climate, the natural way of lowering the temperature is high ceilings with ventilators. The studies also have shown that the variation in temperature or thermal level can be up to $4^{\circ} \mathrm{C}$ because of the height of the ceiling or good ventilation or both of them [6]. Ventilation is also effective in maintaining the air quality and comfort; the poor indoor air quality is the fourth largest environmental threat to the world [7].

Ventilation is needed for the discharge of air from inside 
to outside and to get fresh outside air to decrease indoor poisons, dampness, and smells. Contaminants, for example, formaldehyde, unstable natural mixes, and radon can gather in inadequately ventilated homes. Abundance dampness in a home can create high moistness. Static air can promote harmful ingredients such as toxic gases in homes. When too minimal open-air enters a home, toxins can once in a while aggregate to levels that can present wellbeing and solace issues. Moreover, one way to deal with bringing down the convergences of indoor air toxins in the house is to expand the measure of open-air coming in. There are various mechanical ventilation gadgets, from exhaust fans that discontinuously expel air from a solitary room, for example, restrooms and the kitchen, to air dealing with frameworks that utilizes fans and ventilation system to consistently evacuate indoor air and appropriately separate and adapt to open air to vital focuses all through the house. In any case, the cost that we pay for ventilation gadgets, it drives us to keep away from the establishment of ventilators, even where required [8],[9].

The financially savvy framework and vitality sparing is the common ventilation. The common ventilation is the ventilation of a structure with outside air without the utilization of a fan or other mechanical framework. It tends to be accomplished with operable windows when the ventilation requirement is for a small space. The warm air in the structure can raise and exhaust out subsequently driving fresh air from outside to inside the building structure normally through openings in the lower regions [8].

If we look at the efficiency of high ceilings, we can conclude that the system of natural ventilation works well in high ceiling houses, because of the space available for air to rise and move outside which also leaves the area for fresh air. The high ceiling houses are friendlier with a natural ventilation system than low ceiling houses. Cross ventilation can be easily done in high ceiling houses because as warm air rises it gets excess to the outdoor open area through ventilators. This seems difficult in low ceiling houses $[7,10]$. Even people are constructing low ceiling houses due to cost issues. Several studies have been conducted in several climates about environmental thermal behaviour. This study has indicated the influence of ceiling height and the presence of ventilators as a key factor in thermal comfort about good ventilation. The house planned according to the ventilation requirements naturally, would reduce energy consumption as well as expenditures during the building's lifetime. It is also worth mentioning to add height as a rule in countries' building codes [7],[11].

\section{Significance and Objective of the Study}

The research helps the public to decide whether they want to construct and design their houses for natural ventilation, or to design for mechanical ventilation. Natural ventilation through high ceilings may cost high at the time of construction but helps in reducing the cost of ventilation in the building phase of a house. Effective ventilation in the houses is the present-day need, to reduce the use of mechanical ventilation as well as to reduce the energy and cost paid for ventilation. The study is conducted, to compare the temperature verification in both high and low ceiling houses. The other aspect of the study is that the ventilation system not only reduces the temperature but also keeps the house humidity and moisture level to the standard points. The positive points of ventilators are first to reduce the temperature of the house, keep the house cool, energy-efficient, cost-effective, discharge of stagnant air, the entrance of fresh cool air, and maintained levels of humidity, moisture, and dew point.

The main objectives of the study are:

- To analyse the effectiveness of ventilation systems in high ceiling houses.

- $\quad$ To compare the temperature differences in low and high ceiling houses.

\section{Literature Review}

One of the ways to have more cool air in the spaces is through the provision of high ceilings and proper ventilation in warm and humid climate, the present study also focused on this scenario but the alternate of it is a low ceiling in cold climates. Several types of research have been discussed here, in both ways as low ceiling and high ceiling, in conclusion basically to get the solution according to climates. Many types of research focused on thermal comfort concerning cold climates where it is meant to be a collection of warm air inside the buildings.

Hashimoto and Yoneda (2009) presented the variations in ceiling heights and their impacts with thermal load and ventilation through analyzing spaces with CFD softwareComputational Fluid Dynamics - and presented the results. The situation showed that the higher level of air layers is hot and can provide thermal comfort in cold climate [12]. The indoor environmental air quality can be maintained to provide comfortable heat and cold levels which can also result in human comfort and building energy use reduction [13]. Further, the results of Lam and Chan, Zuo and Zhao and Schiavon, Hoyt, et.al. Jradi, Sangogboye, Mattera, Kjærgaard, Veje, Jorgensen in their respective researchers analyzed that thermal environments presented temperature verifications in buildings [14],[15],[13],[11].

Guimares et al. studied the impact of ceiling height and thermal comfort of buildings in Brazil as a hot weather location. The ceiling height has been varied of $2.4 \mathrm{~m}, 2.8 \mathrm{~m}$, and $3 \mathrm{~m}$. Results showed that temperature increases $1{ }^{\circ} \mathrm{C}$ per each $20 \mathrm{~cm}$. The high and low airwaves can vary up to $4{ }^{\circ} \mathrm{C}$. The Upper and lower layers of the indoor environment can reach up to $4^{\circ} \mathrm{C}$ [6]. Ghafari, Mirrahimi, Heidari also address the issue of the neglected area in the field of 
influence of ceiling height on heating energy consumption in the cold climate still has not been dealt with in-depth. This paper sheds new light on reducing the heating energy consumption by conducting the variation of ceiling height [16].

\subsection{The Need for Natural Ventilation}

Aside from vitality issues, ventilation is significant, because it influences private air quality, which thusly influences wellbeing, solace, and building usefulness. Verifiably, a blend of penetration from flawed envelopes and inhabitant-controlled openings (for example windows) ventilated our homes. Until the vitality emergency of the 1970s, numerous individuals thought this ventilation was adequate without administrative intercession, and there was less worry about the private indoor condition. Today, the Environmental Protection Agency records that to maintain the quality of air inside the rooms is the fourth biggest ecological risk to our reality. This expanded familiarity with the indoor condition is because of a few subjective changes in our homes. One change is that new houses are more vitality productive because of improved development strategies, for example, diminished air spillage, expanded protection levels [7].

\subsection{The Purpose of Natural Ventilation}

The buildings need ventilation for the exchange of air from inside to outside to diminish indoor poisons, the suddenness, and aromas. Toxins and impurities, for instance, formaldehyde, eccentric normal blends, and radon can accompany the homes without ventilation. The American Society of Heating, Refrigerating and Air-Conditioning Engineers suggest having proper ventilation in homes at a pace of 0.35 air changes each hour or 15 cubic feet for every individual each minute. If too minimal open-air enters a home, contaminations can some of the time amass to levels that can present wellbeing and solace issues [7]. Similarly, one way to deal with bringing down the convergences of indoor air poisons in your house is to expand the measure of outside air coming in.

The air crossing is possible because of penetration and ventilation whether natural or mechanical. When the air flows into the house at a fast speed it travels and cool or warm down the temperature inside the rooms. When the speed of air is slow inside the rooms, the air contamination may remove slowly [7],[17]. Most of the houses have mechanical devices and exhaust fans for the removal of contaminated or warm air, including fumes outside the home [18]. In a perfect world, new homes will be worked to limit spillage to control vitality misfortune, improve comfort, and limit the vehicle of dampness and contaminations through the structure shell. These homes should then additionally have mechanical ventilation to expel contaminations produced in the home and give open air in a controlled way. Regardless of whether a mechanical ventilation framework bodes well in your current homes relies upon the house, your current warming, ventilation, and cooling (HVAC) framework, and the progressions you have arranged [7],[13].

\subsection{Cost for a Fully Naturally Ventilated Building}

Structures that utilize natural ventilation may cost high because the openings and windows increase in construction cost as windows cost $5 \%$ to $10 \%$ more than a wall covering, yet the reserve funds from not utilizing cooling will counterbalance this additional expense. Half and half frameworks of open ducts will be increasingly costly in light of the greater expense for operable windows and interlocking controls for the HVAC framework. Expenses shift incredibly relying upon the establishment of heating, ventilation, and air conditioning (HVAC) framework, the cost is decided on the intricacy of the framework and the functions programmed or controlled [7].

\subsection{Indoor Air Quality and Pollution}

With the deficiency in home ventilation, toxins can develop and turn out to be extremely thought. These poisons originate from numerous sources, are progressively hazardous when joined with high moistness levels, which is another issue related to the lack of ventilation in homes. At the point when humidity is excessively high, the decay of inside interior can become major issues. Another issue with high dampness is dust bugs. Each home has dust vermin and they flourish in moist surroundings. That is the condition to worry for individuals who experience the ill effects of residue vermin sensitivities [14,20,19,21].

The carbon components can raise the toxins inside the home without proper ventilation. Proper ventilation in homes can help lessen sensitivity and asthma side effects and can aid in the curing of respiratory issues that weight a huge number of individuals [20]. Low moistness, then again, can be a reason of throat and nose bothering and dry skin. The danger from pets, pollen allergies, lead, mole spores, dust mites, tobacco smoke, chemicals, paints, and pesticides can be a portion of the regular toxins that can develop without satisfactory home ventilation [22].

\subsection{Natural Cross-ventilation}

The cross ventilation relies upon two ceaselessly evolving components: wind accessibility and wind course. Thusly, it is a to some degree questionable hotspot for giving wind stream and warm solace. In cross ventilation, the breeze makes a high-pressure area to affect the structure and a low-pressure area on the lower side (Figure 1). Weight is most noteworthy close to the focal point of the windward divider lessening to the corners as the air 
finds different approaches for movement around the structure so air admissions are best close to the inside or the high-pressure zones [22],[23]. The open area for ventilation is approximately $25 \%$ and smaller for small spaces. The airflow must reach in congested areas [24].

Natural ventilation is the ventilation of a structure without the utilization of a fan or other mechanical framework. It tends to be accomplished with operable windows when the space is small. In progressively complex frameworks, warm air in the structure can be raised and went out from the upper vents to the outside in this way driving fresh, low-temperature air to come inside the structure normally through the vents in the lower regions. These frameworks utilize next to no vitality, however care must be taken to guarantee the inhabitants' solace. In a hot and humid climate like in our region, the warm air raises automatically regularly. Air-side economizers play out a similar capacity as characteristic ventilation, however, utilize mechanical frameworks' fans, pipes, dampers, and control frameworks to present and convey cool open-air when fitting [23].

Wind striking a building generates a region of higher pressure in the direction of its incidence (windward wall) while the sides, i.e., leeward wall and roof are subjected to a reduced pressure. A pressure gradient created in the direction of the incident wind causes the air to flow through openings in the buildings. Windows play a dominant role in inducing ventilation. Ventilation rate is affected by climate, wind direction, size of inlet and outlet openings, volume of the room, shading devices and the internal partitions [25]. Evans studied the effect of air flow related to the position of inlet and outlets in the wall. The actual wind flow in the building is due to the combined effect of thermal and wind forces [26].

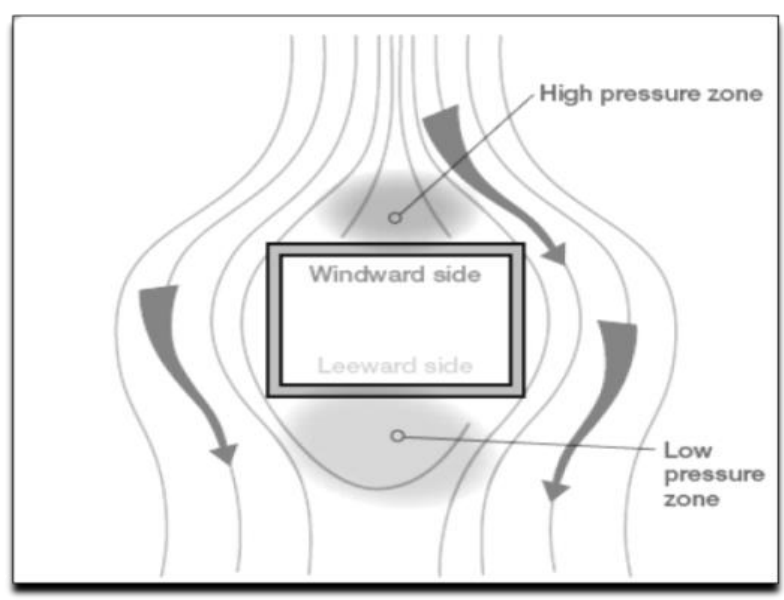

Figure 1. Pressure Effect of wind on the building

\subsection{Low Ceiling Houses}

Low ceiling houses range from nine feet to ten feet in height, even less than this. In the present situation, people preferred a low ceiling house to reduce the cost of construction. These houses require mechanical devices used for ventilation which increases the energy consumption and cost expenditures of the building while in use because of low ceiling houses without ventilators have minimum outlets for exchange of air. It also increased the need for cooling the house in summer by split conditioners and fans. These things use electricity which we cannot make by ourselves so we pay for it. Low ceiling houses reduce the cost at the time of construction but raise the cost we pay later on for mechanical ventilation. Because air cannot pass freely from these houses so they remain humid and warm. The house size restricted people to the indoor environment of the house and they live with artificial means of cooling and ventilating the house. Even these artificial methods are used for comfort but they are also having side effects on the human body such as ultra-violate rays coming out of air conditioners and freezers then heat gain in nature which is also damaging the ozone layer [27].

\subsection{High Ceiling Houses}

In the past decades, most of the houses were constructed with a high ceiling almost eleven to thirteen feet high. The benefits which they provide to the residents are that high ceiling raises the efficiency of the ventilation process. They are more-airy, cool, and lower in temperature. They provide an automatic or natural system to ventilation which also controls humidity, moisture, and dew point with in the rooms, a natural ventilation system works on the principle of osmosis that if the air has more contamination, it will go towards the air which has low contamination and will exchange to balance the air contents . A common person might be unaware of the benefits of those houses and wish to build high ceilings just because of trends of those times. But now it is open that the high ceilings also contributed to ventilation and cooling. Now the need is to create awareness in people about its benefits and if go into the depth, those houses not only contribute to ventilation but too many other factors adjoined with ventilation. There is not any best method than to ventilate the house by natural ways and high ceilings are very convenient to build and to get their benefits [17],[21],[22],[24],[27],[28].

\section{Research Methodology}

The research is based on quantitative survey approach to compare the efficiency of ventilation systems in the high ceiling and low ceiling houses.

\subsection{Sample}

The sample consists of High Ceiling Houses and Low Ceiling Houses in warm-humid climate of Pakistan. Two different localities are selected in the city of Lahore because these localities were having both types of houses, $\mathrm{HCH}$ and $\mathrm{LCH}$, required for the study. The two localities 
are Samanabad and Iqbal Town of Lahore. The total sample size was twenty houses.

\subsubsection{Sample Description}

They range from ten marlas (2723sqft.) to one kanal houses (5445sqft).

Their specific features are mentioned with each of them about elevation features such as surrounded by trees, buildings, open areas, etc.

Most of them are fully constructed on the ground floors with two to three rooms on the first floor.

\subsubsection{Low Ceiling Houses}

They are having low ceilings that are almost 9' to 10' (feet). Some of the houses were having a false ceiling and all houses were not having ventilators at the upper level of walls, in the rooms which were included in the study. Even the windows were present but most of the house habitants were using air conditioning devices (Fig 2).



Figure 2. Low Ceiling with Cooling Device and Small Window

\subsubsection{High Ceiling Houses}

They are having high ceilings than low ceiling houses that are almost 11' to 13 ' (feet) with ventilation. The ventilation is provided through ventilators or large windows (Fig 3). Ventilators were present in most of the rooms at the upper level on the walls in the rooms, which were included in the study.



Figure 3. High Ceiling with windows

\subsubsection{Instrumentation}

The Mercury Thermometer is used to measure climatic ambient air temperature.

\subsection{Data Collection}

The residents of selected sample houses are involved in the study. They are provided with the instruments to measure the inside temperature of the house. They noted down the temperature daily. The temperature was recorded three times during the day. The researcher was provided a file to be filled by the residents daily. Time to note the temperature was tried to be fixed in the morning, afternoon, and evening. The study was limited to the city of Lahore and the duration for the study is twenty days starting from $27^{\text {th }}$ December to the $15^{\text {th }}$ of January and only twenty houses were selected (ten high ceiling and ten low ceiling houses).

\section{Data Analysis and Interpretation}

The data was collected from the residents after the end of the duration and analysed by statistical terms. The data taken from the weather department was also used to analyse and compare the differences in temperatures. The averages were counted of the data taken from the house to evaluate the effectiveness of the ventilation process and temperature differences. The mean temperature of low and high ceiling houses and the difference in mean temperature in residents' recorded temperature and temperature by the Weather Meteorological department (WMD) is given in Table 1.

\subsection{Low Ceiling Houses}

Mean Temperature of Ten Houses $=154.35^{\circ} \mathrm{C} / 10=$ $15.43^{\circ} \mathrm{C}$

Mean. Temp. of Twenty Days by Weather Metallurgical Department $(\mathrm{WMD})=9.9^{\circ} \mathrm{C}$.

The difference in the Temperature taken from Houses and from the WMD $=15.43-9.9=5.53^{\circ} \mathrm{C}$.

\subsection{High Ceiling Houses}

The Mean Temperature of Ten Houses $=138.01^{\circ} \mathrm{C}$ $/ 10=13.80^{\circ} \mathrm{C}$.

The Mean Temperature of Twenty Days by Weather Metallurgical Department $(\mathrm{WMD})=9.9^{\circ} \mathrm{C}$.

The difference in the Temperature taken from Houses and from the $\mathrm{WMD}=13.80-9.9=3.9^{\circ} \mathrm{C}$

The temperature differences of $5.53^{\circ} \mathrm{C}$ and $3.9^{\circ} \mathrm{C}$, respectively in $\mathrm{LCH}$ and $\mathrm{HCH}$ show that the overall temperature of houses recorded by WMD varied which shows that the LCH have high temperature [29], [30]. The difference of $1.43^{\circ} \mathrm{C}$ in temperatures of $\mathrm{LCH}$ and $\mathrm{HCH}$ also concluded that $\mathrm{HCH}$ has low temperatures because of ventilators. 
Table 1. Difference in mean temperature recorded by Residents and WMD.

\begin{tabular}{|c|c|c|c|}
\hline Mean Temp. & $\begin{array}{c}\text { Temp. recorded } \\
\text { by Residents } \\
\left({ }^{\circ} \mathrm{C}\right)\end{array}$ & $\begin{array}{c}\text { Temp. recorded } \\
\text { by WMD } \\
\left({ }^{\circ} \mathrm{C}\right)\end{array}$ & $\begin{array}{c}\text { Difference } \\
\text { in Temp. } \\
\text { Mean }\left({ }^{\circ} \mathrm{C}\right)\end{array}$ \\
\hline $\begin{array}{c}\text { Low Ceiling } \\
\text { Houses }\end{array}$ & 15.43 & 9.9 & 5.53 \\
\hline $\begin{array}{c}\text { High Ceiling } \\
\text { Houses }\end{array}$ & 13.87 & 9.9 & 3.9 \\
\hline
\end{tabular}

\subsection{Comparison of Average Temperature in Houses}

Average temperatures of the low ceiling and high ceiling houses have been compared graphically by using multiple bar charts. Figure 4 shows the comparison of average temperature in $\mathrm{LCH}$ and $\mathrm{HCH}$. It can be seen that the average temperatures in $\mathrm{LCH}$ are higher than the $\mathrm{HCH}$.

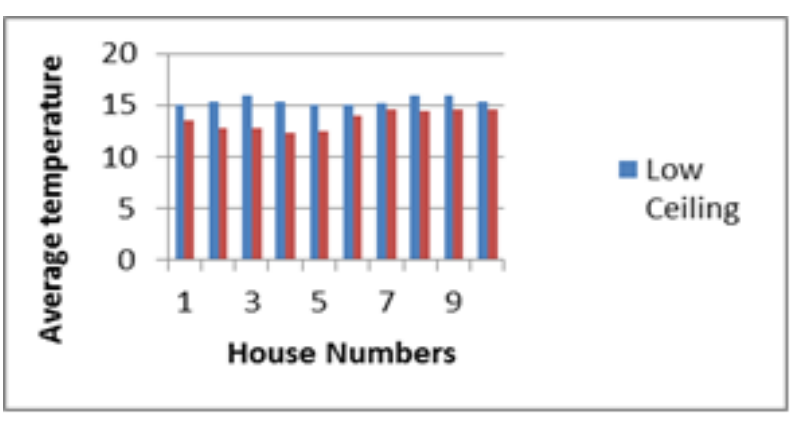

Figure 4. Comparison of Average Temperature in Low and High Ceiling Houses.

\subsection{Testing of Hypothesis}

Data on temperature for $\mathrm{LCH}$ and $\mathrm{HCH}$ were analyzed by applying independent sample T-test to check the significance of the difference between the temperatures of two kinds of houses.

The Null and Alternative hypotheses are stated as under:

$\mathrm{H} 0$ : There is no significant difference between the average temperature of low ceiling houses and high ceiling houses with ventilators.

H0: There is a significant difference between the average temperature of low ceiling houses and high ceiling houses with ventilators.

Level of Significance: $5 \%$.

\subsection{Test Results}

The data were analyzed using Statistical Package for Social Sciences (SPSS) and the results are stated in table 2.

Table 2. Data and Average Temperature of Low and High Ceiling Houses

\begin{tabular}{|c|c|c|c|c|c|}
\hline$\cdot$ & Group & $\mathrm{N}$ & Mean & $\begin{array}{c}\text { Std. } \\
\text { Deviation }\end{array}$ & $\begin{array}{c}\text { Std. } \\
\text { Error } \\
\text { Mean }\end{array}$ \\
\hline t.var & I & 200 & 15.31 & 2.86 & .20225 \\
\hline t.var & II & 200 & 13.88 & 2.78 & .19659 \\
\hline
\end{tabular}

Table 2 shows the summary of the statistical analyses performed on the data.

Group 1 represents LCH and Group II represents high ceiling houses. It can be seen that the average temperature of $\mathrm{HCH}$ is less which is $13.88{ }^{\circ} \mathrm{C}$ than $\mathrm{LCH}$ which is $15.31^{\circ} \mathrm{C}$. Average so it is visible that high ceiling designs with ventilators are effective in lowering the temperature.

Table 3. T-Test Results and Mean Difference of Temperature.

\begin{tabular}{|c|c|c|c|c|c|}
\hline$\cdot$ & $\mathrm{T}$ & $\mathrm{df}$ & $\begin{array}{c}\text { Sig. } \\
(2 \text {-tailed) }\end{array}$ & $\begin{array}{c}\text { Mean } \\
\text { Difference }\end{array}$ & $\begin{array}{c}\text { Std. Error } \\
\text { Difference }\end{array}$ \\
\hline t.var & 5.114 & 398 & .000 & 1.442 & .28205 \\
\hline
\end{tabular}

Table 3 shows the value of $\mathrm{t}$-Statistic $=5.114$ along with the degrees of freedom=398 and the P-value (sig. 2-tailed) $=0.000$, and the mean difference of temperature $=1.44^{\circ} \mathrm{C}$.

\subsection{Analysis of the T-Test}

As the P-value of the test $=0.00<0.05$ (assumed level of significance) which indicates that the null hypothesis is rejected. It can be concluded that there is a significant difference in the mean temperature of HCH and LCH. It is also evident that the mean temperature of $\mathrm{HCH}$ is less than that of $\mathrm{LCH}$.

\section{Discussion and Conclusions}

Environmental degradation is because of the resource unlimited and unrealistic use but careful consideration of materials and methods to use resources can reduce the negative impacts on humans [1],[2],[3]. One of the methods is ventilation, even we are spreading a lot on mechanical ventilation but natural ventilation is also effective [7]. People consider a low ceiling for the cost issues but researches favored a high ceiling for natural ventilation and air quality [8],[9]. The researcher tried to select the sample which would be having the same features such as lawn, back yard, trees, plants, etc. the temperature of selected sample houses was recorded thrice daily. It was concluded that the ventilation process is affected by the height of the ceiling and the use of ventilators, higher the ceiling height the lower is the temperature. The analysis of the data showed the difference in temperature is highly significant and high ceiling houses have lower average temperatures than $\mathrm{LCH}$. This temperature difference would affect the inner environment to keep it cool and that is because of the efficiency of ventilation in high ceiling houses so the height of the ceiling can contribute to the ventilation system. The ventilation process works more effectively in high ceiling houses than LCH. The temperature difference in $\mathrm{LCH}$ and $\mathrm{HCH}$ is $1.44^{\circ} \mathrm{C}$ so the hypothesis i.e. the ventilation system is more effective in cooling the houses constructed with high ceilings than houses with low ceilings is accepted [25],[28]. Some of the design issues are also mentioned here which were 
concluded from the literature such as cross ventilation is very effective in homes, the windows must cover $25 \%$ area of the room size, the ventilators work more successfully at a height in rooms and the ventilators need to cover $1 / 20$ of the floor area [17],[23].

The findings of the study show the effectiveness of the ventilation system in high ceiling houses. Now a day's people mostly started construction with low ceilings, to minimize the cost of construction. People use to construct a false ceiling to lower the height of the ceiling that maximizes the cost of construction. This helps in keeping the house cool in summers but it is not effective in air movement and ventilation. The facts are telling that even a low ceiling is cost-effective at the time of construction but in the long run, a high ceiling helps to reduce the cost paid for ventilation and cooling of the house. The study can also, be replicated between the high ceiling houses with and without ventilators.

\section{Acknowledgements}

The researchers are grateful to the owners of the houses who helped in the study for the data collection and temperatures of their houses.

\section{REFERENCES}

[1] P. M. Hu, Cunningham, S. Gilloran, Sustainable Design Rating System Comparison Using a Life-cycle Methodology. Building Environment, vol. 126, pp. 410-421, 2017.

[2] C. V. Subramanian, N. Ramachandran, S. S. Kumar, A review of passive cooling architectural design interventions for thermal comfort in residential buildings. Indian Journal of Scientific Res, vol. 14, no. 1, pp. 163-172, 2017.

[3] J. Zuo, Z. Y. Zhao. Green building research- current status and future agenda: A review," Renewable \& Sustain. Energy Review, vol. 30, pp. 271-281, 2014.

[4] M. A. Kamal. Reinventing Traditional System for Sustainable Built Environment: An Overview of Passive Downdraught Evaporative Cooling (PDEC) Technique for Energy Conservation, Journal of Research in Architecture and Planning, 11 (2), 56-62, 2011.

[5] D. Prakash, P. Ravikumar. Study of thermal comfort in a room with windows at adjacent walls along with additional vents. Indian Journal of Science and Technology. Jun; 6(6):4659-69, 2013.

[6] R. P. Guimaraes, M. C. R. Carvalho, F. A. Santas, The influence of ceiling height in thermal comfort of buildings: A case study in Belo Horizonte, Brazil," Int. Journal of House Science, vol. 37, no. 2, pp. 75-86, 2013.

[7] ASHRAE, ANSI/ASHRAE Standard 62-1989, Ventilation for Acceptable Indoor Air Quality. Atlanta: American Society of Heating, Refrigerator and Air Conditioning
Engineers, Inc., 1989.

[8] Hawaii Commercial Building Guidelines for Energy Efficiency, Online available from www.archenergy.com/Lib rary/General//Chapter2_Nat_Vent_030604.Pdf.

[9] C. Georgakis, M. Santamouris. Experimental investigation of airflow and temperature distribution in deep urban canyons for natural ventilation purposes. Energy and Buildings, 38(4), 367-376, 2006.

[10] Evelina, High or low ceiling? Advantages, disadvantages, Online available from https://www.e-interjeras.lt/en/blog/hi gh-or-low-ceiling-advantages-disadvantages 28th feb 2016. Retrieved 13th Jan.2020.

[11] M. Jradi, F. C. Sangogboye, C. G. Mattera, M. B. Kjærgaard, C. Veje, B. N. Jørgensen. A World Class Energy Efficient University Building by Danish 2020 Standards," Energy Procedia, vol. 132, pp. 21-26, 2017.

[12] Y. Hashimoto, H. Yoneda. Numerical Study on the Influence of a Ceiling Height. Eleventh International IBPSA Conference. Glasgow, Scotland, 2009.

[13] S. Schiavon, T. Hoyt, A. Piccioli, Web application for thermal comfort visualization and calculation according to ASHRAE Standard 55, Building Simulation, vol. 7, no. 4, pp. 321-334, 2014.

[14] D. B. Crawley, J. W. Hand, M. Kummert, B. T. Griffith, Contrasting the capabilities of building energy performance simulation programs, Building and Environonment, vol. 43 , no. 4, pp. 661-673, 2008.

[15] J. Zuo, Z. Y. Zhao. Green building research- current status and future agenda: A review," Renewable Sustainable Energy Review, vol. 30, pp. 271-281, 2014.

[16] F. Ghafari, S. Mirrahimi, S. Heidari, Influence of ceiling height on heating energy consumption in educational building Online available from https://www.researchgate.ne t/publication/325022206, 2018

[17] Ventilation for Homes, U.S. Environmental Protection Agency, Online available from http://www.Lungusa.Org/As thma/Ascpedfac99.Html. September 1999

[18] B. Wang, A. Malkawi. Design-based natural ventilation evaluation in early-stage for high-performance buildings. Sustainable cities and society, 45, 25-37, 2019.

[19] N. Chilengwe, S. Sharples. Low and High-Pressure Experimental Analysis of Ventilators for Natural Ventilation in Buildings. International Journal of Ventilation 2:2, pp. 149-158, 2003.

[20] D. B. Crawley, J. W. Hand, M. Kummert, B. T. Griffith, Contrasting the capabilities of building energy performance simulation programs, Building Environment, vol. 43, no. 4, pp. 661-673, 2008.

[21] Passive solar guidelines (Residential) Online available from www.greenbuilder.com/Sourcebook/Passsolguide3.html

[22] I. Seginer, A. Livne, A. Effect of ceiling height on the power requirement of forced ventilation in greenhouses. In Symposium on Potential Productivity in Protected Cultivation 87, pp. 51-68, 1978.

[23] U. Paase, F. Battaglia, Designing spaces for Natural 
ventilation: An Architect's Guide, Routledge, New York, USA. 2015.

[24] D. Mudarri, Public health consequences and cost of climate change impacts on indoor environments. US Environmental Protection Agency, 2010.

[25] M. A. Kamal, Energy Responsiveness in Traditional Residential Buildings of Lucknow', an unpublished Ph.D. Thesis, Indian Institute of Technology, Roorkee, India, 2007.

[26] B. H. Evans, Energy Conservation with Natural Airflow Through Windows. ASHRAE Transactions, 852, 1979.

[27] E. Skaret, M. M. Mathisen. Ventilation efficiency: A guide to efficient ventilation. ASHRAE Trans, USA, pp. 89, 1983.
[28] D. Brown, Alternatives to modern air-conditioning systems: using natural ventilation and other techniques. APT Bulletin: The Journal of Preservation Technology, 27(3), 46-49, 1996.

[29] Handbook Data, Weather Meteorological Department, Jail Road, Lahore, 2018.

[30] J. Yao, N. Zhu, Evaluation of indoor thermal environmental, energy, and daylighting performance of Thermotropic windows. Building and Environment, 49, 283-290, 2012.

[31] N. Walikewitz, B. Jänicke, M. Langner, F. Meier, W Endlicher, The difference between the mean radiant temperature and the air temperature within indoor environments: A case study during summer conditions. Building and Environment, 84, 151-161, 2015. 